\title{
Metadata Correction: Engaging a Community for Rare Genetic Disease: Best Practices and Education From Individual Crowdfunding Campaigns
}

Romina Alicia Ortiz, MHS; Steven Witte, MD, PhD; Arvin Gouw, PhD; Ana Sanfilippo, MBA; Richard Tsai, MSc; Danielle Fumagalli, MA; Christine Yu, MPH; Karla Lant, BA; Nicole Lipitz, BA; Jennifer Shepphird, PhD; Fidelia B Alvina, BA; Jimmy Cheng-Ho Lin, MPH, MD, PhD

Rare Genomics Institute, Downey, CA, United States

\section{Corresponding Author:}

Romina Alicia Ortiz, MHS

Rare Genomics Institute

8504 Firestone Blvd \#198

Downey, CA, 90241

United States

Phone: 15624132581

Email: romina.ortiz@raregenomics.org

\section{Related Article:}

Correction of: http://www.i-jmr.org/2018/1/e3/

(Interact J Med Res 2018;7(1):e10707) doi: 10.2196/10707

In the paper by Ortiz et al, "Engaging a Community for Rare Genetic Disease: Best Practices and Education From Individual Crowdfunding Campaigns" (Interact J Med Res 2018;7(1):e3), author Nicole Lipitz's last name was incorrectly spelled as "Lipintz". This has now been corrected.
The corrected article will appear in the online version of the paper on the JMIR website on April 27, 2018, together with the publication of this correction notice. Because this was made after submission to PubMed, PubMed Central, and other full-text repositories, the corrected article also has been re-submitted to those repositories.

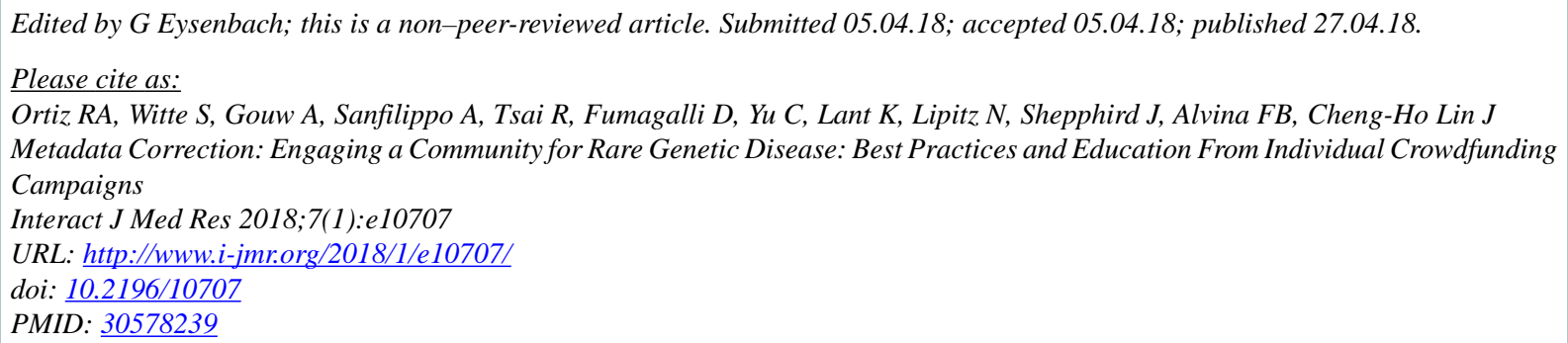

CRomina Alicia Ortiz, Steven Witte, Arvin Gouw, Ana Sanfilippo, Richard Tsai, Danielle Fumagalli, Christine Yu, Karla Lant, Nicole Lipitz, Jennifer Shepphird, Fidelia B Alvina, Jimmy Cheng-Ho Lin. Originally published in the Interactive Journal of Medical Research (http://www.i-jmr.org/), 27.04.2018. This is an open-access article distributed under the terms of the Creative Commons Attribution License (https://creativecommons.org/licenses/by/4.0/), which permits unrestricted use, distribution, and reproduction in any medium, provided the original work, first published in the Interactive Journal of Medical Research, is properly cited. The complete bibliographic information, a link to the original publication on http://www.i-jmr.org/, as well as this copyright and license information must be included. 